\title{
VIDEO PROFILE JURUSAN SISTEM KOMPUTER JENJANG STRATA SATU PADA STMIK RAHARJA TANGERANG
}

\author{
Adi Kusuma Widya Tama ${ }^{1}$, Azwar Aditya Putra ${ }^{2,}$ Muhamad Azis Fikri ${ }^{3}$ \\ ${ }^{1,2}$ Dosen STMIK Raharja Jurusan Teknik Informatika ${ }^{3}$ Mahasiswa STMIK Raharja Tangerang \\ Jurusan Teknik Informatika \\ 1,2,3 STMIK Raharja, Jl. Jenderal Sudirman No. 40 Modern Cikokol - Tangerang \\ e-mail: ${ }^{1}$ adi.kusuma@raharja.info, ${ }^{2}$ azwar.aditya.p@raharja.info, ${ }^{3}$ azis.fikri@raharja.info
}

\begin{abstract}
Abstrak
Saat ini banyak lembaga pendidikan formal maupun non formal yang bersaing untuk mendapatkan calon mahasiswa/i baru, untuk itu profile suatu lembaga pendidikan menjadi indentitas penting dalam memperkenalkan lembaga tersebut ke masyarakat umum. Berbagai macam cara digunakan untuk mensosialisasikan profilnya, salah satunya STMIK Raharja Tangerang. Di era modern ini, multimedia sangat berperan penting dalam bidang pemasaran sebagai promosi. Tujuan penelitian ini yaitu, agar calon mahasiswa/i baru berminat pada Jurusan Sistem Komputer, serta sebagai sarana informasi dan promosi yang efektif dan menarik bagi masyarakat umum. Permasalahannya, program promosi Jurusan SK sebelumnya baru menggunakan media brosur dan spanduk yang informasinya kurang lengkap dan menarik, untuk itu Jurusan SK membutuhkan media video profile yang mampu memberikan informasi secara detail dan menarik mengenai jurusan Sistem Komputer, Adapun metode penelitiannya yaitu : analisa permasalahan, pengumpulan data, analisa perancangan media dan, konsep produksi media (KPM). Hasil penelitiannya berupa media video profile Jurusan Sistem Komputer, yang menjelaskan profile Jurusan Sistem Komputer STMIK Raharja meliputi kosentrasi CCIT dan Computer System, metode pembelajaran, keunggulan, dan fasilitasnya. Dengan adanya perancangan media video profile jurusan Sistem Komputer STMIK Raharja dapat menjadi daya tarik untuk meningkatkan minat calon mahasiswa/i baru di Jurusan tersebut, dan menjadi media yang informatif dan bermanfaat bagi masyarakat umum.
\end{abstract}

Kata Kunci : Video Profile, Promosi, Informasi

\begin{abstract}
Currently, many formal and non formal education institutions are competing to get new students, so the profile of an educational institution becomes an important identity in introducing the institution to the general public. Various ways are used to socialize his profile, one of them STMIK Raharja Tangerang. In this modern era, multimedia plays an important role in the field of marketing as a promotion. The purpose of this study is, for prospective students / $i$ new interested in the Department of Computer Systems, as well as a means of information and promotion effective and attractive to the general public. The problem is, the previous SK's promotional program only uses the brochure and banners media which information is not complete and interesting, for that SK Department requires video profile media capable of providing detailed information and interesting about the Department of Computer Systems, The research methods are: problem analysis, data, media design analysis and, media production concept (KPM). The results of his research in the form of video video profile Department of Computer Systems, which explains the profile of Computer Systems Department STMIK Raharja include CCIT and Computer System concentration, learning methods, excellence, and facilities. With the design of video media profile majors Computer Systems STMIK Raharja can be an attraction to increase interest in prospective new students in the Department, and become an informative and useful media for the general public.
\end{abstract}

Keywords : Video Profile, Promotion, Information

Vol 4 No 2 - Agustus 2018 


\section{PENDAHULUAN}

Di era modern seperti sekarang ini, Banyak Instansi pendidikan memanfaatkan media video sebagai sarana untuk meginformasikan dan mempromosikan atau sebagai identitas instansinya. Secara asasnya video adalah alat atau media yang dapat menunjukkan benda yang nyata[1].

Dalam menginformasikan suatu jurusan di Instansi pendidikan, membutuhkan media berupa video profile yang menarik dan merincikan secara detail jurusan yang dijelaskan pada jurusan tersebut. Karena video profile adalah sebuah gambaran informasi tentang riwayat seseorang atau sebuah instansi yang telah mencapai suatu pencapaian[2]. Video juga merupakan media yang paling lengkap, karena mempunyai unsur gerak, suara, dan visualisasi yang nyata. Video profile juga bisa menjadi sarana promosi yang efektif suatu Jurusan agar diminati banyak orang sehingga tercapai keberhasilan dalam mencapai target pendaftar, karena Promosi adalah suatu bentuk komunikasi pemasaran[3].

Jurusan Sistem Komputer merupakan salah satu Program Studi Strata Satu pada STMIK Raharja yang mempunyai 2 konsentrasi yaitu Creative Communication Inovation Technology (CCIT) dan Computer System. Konsentrasi unggulan di Jurusan ini adalah Creative Communication Inovation Technology (CCIT). Tujuan dari penelitian ini adalah untuk lebih memberikan informasi sekaligus untuk mempromosikan jurusan Sistem Komputer STMIK Raharja kepada calon mahasiswa/i yang ingin bergabung pada jurusan Sistem Komputer tersebut.

Permasalahan yang terdapat pada jurusan Sistem Komputer STMIK Raharja sebelumnya adalah, media promosi atau informasi jurusan Sistem Komputer sebelumnya hanya berupa media cetak. Sedangkan, Promosi adalah upaya untuk memberitahukan atau menawarkan produk atau jasa dengan tujuan untuk menarik calon pembeli [4]. Tidak bisa dipungkiri bahwa kebanyakan orang lebih suka mendengar dan menonton dari pada membaca, maka dari itu media video profile dibutuhkan untuk memperkenalkan dan menginformasikan seluruh aspek jurusan Sistem Komputer STMIK Raharja. Perancangan media video profile dibutuhkan oleh bagian Marketing dalam rangka menginformasikan jurusan SK kepada calon mahasiwa/i untuk mendaftar. Selain itu Jurusan SK STMIK Raharja belum mempunyai media yang efektif dalam menginformasikan secara rinci tentang profil, keunggulan, fasilitas serta system pembelajaran yang ada di jurusan SK STMIK Raharja.

Hasil penelitian ini berupa perancangan media video profile dengan alur cerita yaitu menceritakan tentang mahasiswa/i konsentrasi CCIT dan Computer System sedang melakukan aktifitas pembelajaran dengan metode iLearning with iPad, dijelaskan pula keuungulan, visi dan misi serta fasilitas yang ada di jurusan Sistem Komputer STMIK Raharja. Tentunya juga dipadukan dengan effect cinematic dan suara musik menarik yang menjelaskan secara detail tentang CCIT dan Computer System. Implementasi video ini, akan di targetkan kepada calon mahasiswa/i yang berminat mendaftar dan mengambil jurusan Sistem Komputer STMIK Raharja, dan juga sebagai identitas Jurusan SK STMIK Raharja yang merupakan salah satu jurusan unggulan di Perguruan Tinggi Raharja. Strategi pemasaran yang dilakukan adalah dengan mengimplementasikan video profile ini pada media social seperti Youtube, facebook, dan beberapa event yang diadakan oleh Perguruan Tinggi Raharja.

Melalui perancangan media video profile Jurusan Sistem Komputer jenjang Strata Satu STMIK Raharja tentunya akan meningkatkan peminat jurusan SK setiap tahunnya dan menjadi media yang informatif bagi masyarakat luas.

\section{LITERATURE REVIEW}

1. Penelitian yang dilakukan Santoso $(2014)^{[5]}$ dengan judul "Pembuatan Video Profil Smart Preschool Kepunton Solo". Multimedia menjadi hal yang sangat penting dalam dunia pendidikan, tidak terkecuali untuk mempromosikan dan menginformasikan lembaga pendidikan yang bertujuan untuk meningkatkan jumlah pendaftar, dapat memvisualisasikan lebih real tentang keadaan Preschool Kepunton Solo dan juga menginformasikan kepada masyarakat luas. Perancangan Video Profile ini dapat memudahkan masyarakat untuk mengetahui tentang kegiatan belajar mengajar dan juga fasilitas yang ada Profil Smart Preschool Kepunton Solo. Menggunakan metode penelitian studi kepustakaan, observasi, wawancara, kuisioner, analisa perancangan storyboard, pembuatan video, uji coba dan implementasi. Pembuatan video ini menggunakan beberapa aplikasi pengeditan video yaitu Sony Vegas Pro 11 dan Adobe Audition CS 6. 
2. Penelitian yang dilakukan Mahmudi (2015) ${ }^{[6]}$ dengan judul "Pembuatan Video Profile Sekolah Dasar Negeri Tlogo CV. Bootsector". Menjelaskan tentang SDN Tlogo yang baru memiliki media visual seperti brosur, pamflet, website dan informasi lainnya yang kurang efektif. Maka dibuatlah sebuah Video Profile SDN Tlogo agar media promosi lebih menarik dan tidak monoton. Metode yang digunakan adalah metode pengumpulan data yang diantaranya observasi, wawancara dan dokumentasi. Menggunakan Software editing Pinnacle, tentunya dengan adanya Video Profile SDN Tlogo bisa meningkatkan promosi dan jumlah pendaftar. Jadi pada akhirnya, penelitian ini dapat menjadi media promosi sebagai video dokumenter yang nantinya diharapkan dapat meningkatkan popularitas sekolah.

3. Penelitian yang dilakukan Zevri dan Krisnawan (2015) $)^{[7]}$ dengan judul "Perancangan Media Promosi Jurusan Multimedia SMK Saraswati Salatiga Untuk Meningkatkan Jumlah Siswa Pendaftar". Penelitian ini bertujuan untuk mempromosikan jurusan multimedia di SMK Saraswati Salatiga karena menurunnya jumlah siswa yang mendaftar disebabkan beberapa faktor, seperti persepsi masyarakat bahwa lulusan multimedia susah untuk mencari pekerjaan dan juga kurangnya perhatian sekolah terhadap jurusan multimedia. Menggunakan Metode Analisa SWOT, yang digunakan untuk mencari kelebihan, kelemahan, kesempatan dan ancaman dari kompetitor.

4. Penelitian yang dilakukan Sunarya dkk $(2017)^{[8]}$ dengan judul "Perancangan Media Promosi Video Profile Pada SMA Negeri 15 Kota Tangerang" . Penelitian ini menerangkan tentang perancangan Video Profile pada SMAN 15 Kota Tangerang yang berguna untuk mempromosikan dan menginformasikan kepada calon siswa dan masyarakat luas. Sebelumnya bentuk media promosi yang digunakan SMAN 15 Kota Tangerang masih berupa media komunikasi visual, seperti pamflet, spanduk, brosur, dan lainnya. Sehingga SMA Negeri 15 Kota Tangerang membutuhkan media penunjang informasi dan promosi yang lebih menarik dan efektif yaitu dalam bentuk video profile. Implementasi dari video profile ini akan ditujukan kepada calon siswa baru dan masyarakat umum, serta meingkatkan kualitas SMAN 15 Kota Tangerang.

5. Penelitian yang dilakukan oleh Tri Haryanto dan Sarwo Nugroho (2015) ${ }^{[9]}$ dengan judul "Perancangan Video Company Profile Sebagai Media Promosi Perusahaan Pada PT. Propan Raya Icc Semarang”. Media komunikasi dan informasi berupa media visual memiliki kekurangan, dilihat dari segi efisiensi penyampaian informasi dan distribusi, tetapi apabila menggunakan media promosi berupa Video Company Profile, informasi akan lebih efektif dan menarik, karena pengemasannya tidak monoton, dimana penggabungan beberapa file video dan unsur-unsur seperti animasi dan suara, serta packaging menggunakan media keping DVD sehingga lebih efisien.

\section{METODE PENELITIAN}

Ada beberapa metode peneltian yang dilakukan untuk merancang video profile jurusan Sistem Komputer STMIK Raharja, yaitu: (1) Analisa permasalahan yang didapatkan dari bagian pemasaran Perguruan Tinggi Raharja berupa wawancara. (2) Pengumpulan data yang dilakukan dengan cara pengamatan, interview, dan studi pustaka. (3) Analisa Perancangan media video profile yang dibutuhkan oleh jurusan Sistem Komputer STMIK Raharja akan diproduksi dengan software komputer grafis, diantaranya : Adobe Photoshop CS6, Adobe Premiere CS6, Adobe After Effect CS6 dan Adobe Audition CS6, dan metode Konsep Produksi Media (KPM). Perancangan media video profile melalui beberapa proses perancangan agar mendapatkan gambaran tentang project yang dibuat. Sehingga memudahkan kita dalam membuat video profile. Tahapan yang dilakukan adalah sebagai berikut :

\section{Preproduction \\ 2. Production \\ 3. Post Production}




\section{KPM}

\section{PREPRODUCTION}

\section{PRODUCTION}

\section{POST PRODUCTION}

\section{Gambar 1. Konsep Produksi Media}

\section{HASIL DAN PEMBAHASAN}

\section{Preproduction}

Preproduction adalah proses awal suatu karya atau project video yang akan kita mulai yaitu ide, perencanaan, dan persiapan dari KPM. Ada 7 tahapan dalam preproduction dalam konsep produksi media. Mulai dari ide/gagasan yang disalurkan secara sistematis, kemudian pembuatan sinopsis, script writting, dan storyboard, penentuan pemain (talent and crew). Dua langkah terakhir adalah setting alat dan time schedule.

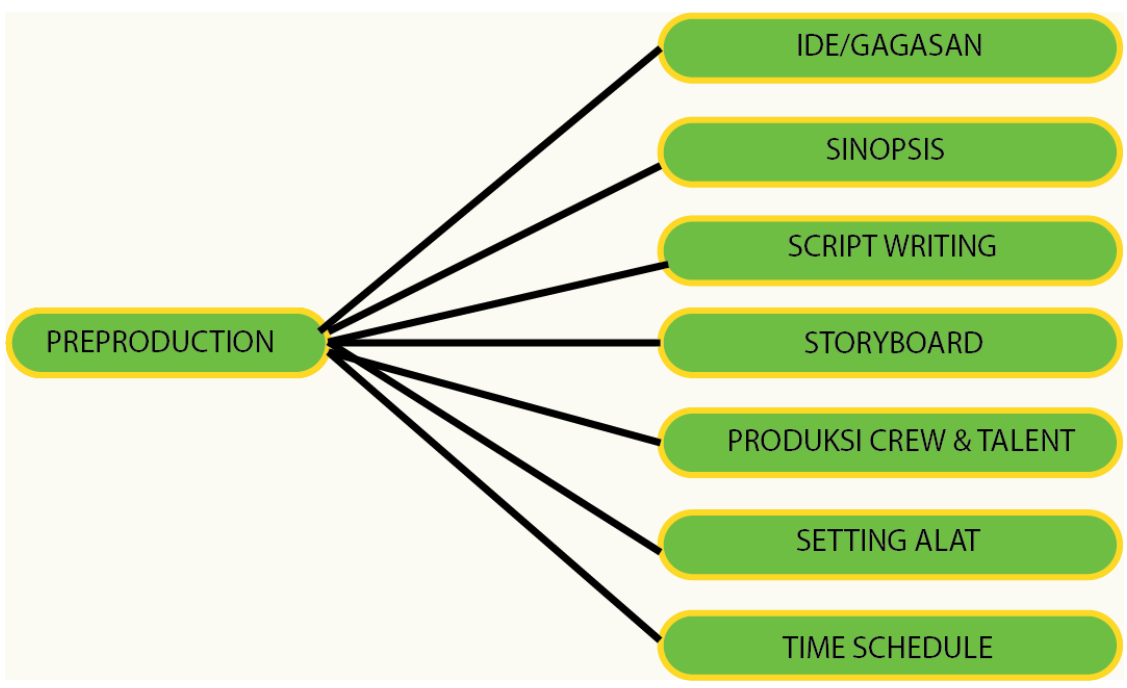

Gambar 2. Preproduction

\section{Ide/Gagasan}

Pembuatan perancangan media video profil ini mengambil ide dari kebanyakan video profil menggunakan konsep yang formal yaitu menampilkan para mahasiswa dan mahasiswi Sistem Komputer sedang melakukan aktifitas perkuliahan seperti biasa dan menampilkan juga keunggulan dan fasilitas dari Jurusan Sistem Komputer.

\section{Sinopsis}

Sinopsis adalah ringkasan sebuah cerita yang akan menjadi patokan dari semua media pembuatan iklan atau film. Berbentuk pemendekan dari sebuah feature documenter tetapi tetap melihat unsur yang ada di dalam feature documenter tersebut. 
Dengan adanya sinopsis bertujuan untuk mengetahui secara singkat alur cerita pada video profil Sistem Komputer STMIK Raharja tersebut.berikut adalah sinopsis dari video profile ini :

"Pertama-tama menampilkan bumper STMIK Raharja disertai dengan efek yang menarik. Lalu menampilkan gedung STMIK Raharja yang berdiri dengan megah, lalu penjelasan dari Jurusan Sistem Komputer disertai dengan Visi, Misi, dan Konsentrasi Jurusan SK, setelah itu ditampilkan juga mengenai kualifikasi tenaga pengajar di Jurusan SK, Kelebihan, Fasilitas dan Prospek Karir lulusan Jurusan SK. Selanjutnya menampilkan Mahasiswa yang sedang praktikum merakit robot di ruang Lab Digital, Mahasiswa dan mahasiswi Sistem Komputer sedang belajar bersama dengan menggunakan metode pembelajaran menggunakan $i P a d$, Mahasiswa SK yang sedang mengikuti perkuliahan di ruang kelas, juga menampilkan mahasiswa di Lab iLearning sebagai salah satu fasilitas yang ada di STMIK Raharja, Kemudian mahasiswa dan mahasiswi Sistem Komputer memakai pakaian toga dan bersemangat menggapai masa depan yang cerah".

Tabel 1. Script Writing

\begin{tabular}{|c|c|c|}
\hline NO. & Visual & Audio \\
\hline 1 & $\begin{array}{l}\text { Bumper Opening menampilkan } \\
\text { gedung depan STMIK Raharja }\end{array}$ & Music \\
\hline 2 & $\begin{array}{l}\text { Menampilkan Visi dan Misi } \\
\text { Jurusan Sistem Komputer STMIK } \\
\text { Raharja }\end{array}$ & $\begin{array}{l}\text { Program Studi Sistem Komputer/ merupakan salah satu } \\
\text { program studi unggulan di Perguruan Tinggi Raharja// }\end{array}$ \\
\hline 3 & $\begin{array}{l}\text { Menampilkan Kualifikasi Tenaga } \\
\text { Pengajar, Jurusan SK,Kelebihan, } \\
\text { Fasilitas, Prospek Karir. }\end{array}$ & $\begin{array}{c}\text { Dengan tenaga pengajar yang professional/ ditunjang } \\
\text { dengan berbagai fasilitas pendukung pembelajaran yang } \\
\text { modern/ menjadikan lulusan program studi Sistem } \\
\text { Komputer yang unggul// }\end{array}$ \\
\hline 4 & $\begin{array}{l}\text { Menampilkan Mahasiswa SK } \\
\text { sedang merakit robot. }\end{array}$ & $\begin{array}{c}\text { Dengan menerapkan keahlian di bidang teknologi } \\
\text { informasi khususnya Creative Communication and } \\
\text { Innovative Technology (CCIT) membuat mahasiswa } \\
\text { semakin inovatif// }\end{array}$ \\
\hline 5 & $\begin{array}{l}\text { Menampilkan Mahasiswa SK } \\
\text { sedang belajar menggunakan } \\
\text { metode iLearning. }\end{array}$ & $\begin{array}{l}\text { iLearning with iPad merupakan salah satu keunggulan/ } \\
\text { dan dapat mempermudah mahasiwa mendapatkan materi } \\
\text { pembelajaran// }\end{array}$ \\
\hline 6 & $\begin{array}{l}\text { Menampilkan Dosen sedang } \\
\text { mengajar dikelas }\end{array}$ & $\begin{array}{c}\text { Metode pembelajaran yang interaktif dan berbasis } \\
\text { multimedia/ membuat para mahasiswa lebih aktif dan } \\
\text { kreatif// }\end{array}$ \\
\hline 7 & $\begin{array}{l}\text { Menampilkan mahasiswa di Lab } \\
\text { iLearning }\end{array}$ & $\begin{array}{l}\text { Program Studi Sistem Komputer memiliki berbagai } \\
\text { fasilitas/ salah satunya Lab iLearning// }\end{array}$ \\
\hline 8 & $\begin{array}{l}\text { Menampilkan mahasiswa } \\
\text { memakai toga dan hotline } \\
\text { Perguruan Tinggi Raharja. }\end{array}$ & $\begin{array}{c}\text { Ayo Bergabung di Program Studi Sistem Komputer } \\
\text { Perguruan Tinggi Raharja/ } \\
\text { Get The Better Future By Computer Sciencel/ }\end{array}$ \\
\hline
\end{tabular}

\section{Rundown}

Rundown merupakan susunan cerita yang dirancang oleh durasi waktu. Berikut merupakan rundown dari Video Profil Sistem Komputer STMIK Raharja : 
Tabel 2. Rundown

\begin{tabular}{|c|c|c|c|c|c|}
\hline No. & Scene & Location & Duration & $\begin{array}{l}\text { INT/ } \\
\text { EXT }\end{array}$ & Description \\
\hline 1. & 1 & - & $\begin{array}{l}\text { 00:00:00- } \\
00: 00: 06\end{array}$ & - & $\begin{array}{c}\text { Bumper Opening } \\
\text { menampilkan gedung } \\
\text { depan STMIK Raharja }\end{array}$ \\
\hline 2. & 2 & - & $\begin{array}{l}00: 00: 07- \\
00: 00: 19\end{array}$ & - & $\begin{array}{c}\text { Menampilkan Visi dan } \\
\text { Misi Jurusan Sistem } \\
\text { Komputer STMIK } \\
\text { Raharja }\end{array}$ \\
\hline 3. & 3 & - & $\begin{array}{l}00: 00: 30- \\
00: 00: 59\end{array}$ & - & $\begin{array}{l}\text { Menampilkan Kualifikasi } \\
\text { Tenaga Pengajar, Jurusan } \\
\text { SK,Kelebihan, Fasilitas, } \\
\text { Prospek Karir. }\end{array}$ \\
\hline 4. & 4 & Lab Digital & $\begin{array}{l}00: 01: 10- \\
00: 01: 30\end{array}$ & $I N T$ & $\begin{array}{c}\text { Menampilkan } \\
\text { Mahasiswa SK sedang } \\
\text { merakit robot. }\end{array}$ \\
\hline 5. & 5 & Lobby & $\begin{array}{l}00: 01: 35- \\
00: 01: 42\end{array}$ & $I N T$ & $\begin{array}{c}\text { Menampilkan } \\
\text { Mahasiswa SK sedang } \\
\text { belajar menggunakan } \\
\text { metode iLearning. }\end{array}$ \\
\hline 6. & 6 & Kelas & $\begin{array}{l}00: 02: 10- \\
00: 02: 36\end{array}$ & $I N T$ & $\begin{array}{c}\text { Menampilkan Dosen } \\
\text { sedang mengajar } \\
\text { dikelas }\end{array}$ \\
\hline 7. & 7. & $\begin{array}{l}\text { Lab } \\
\text { iLearning }\end{array}$ & $\begin{array}{l}00: 02: 40- \\
00: 02: 49\end{array}$ & INT & $\begin{array}{c}\text { Menampilkan } \\
\text { mahasiswa di Lab } \\
\text { iLearning }\end{array}$ \\
\hline 8. & 8. & $\begin{array}{l}\text { Lapangan } \\
\text { STMIK } \\
\text { Raharja }\end{array}$ & $\begin{array}{l}00: 03: 20- \\
00: 03: 25\end{array}$ & $I N T$ & $\begin{array}{c}\text { Menampilkan } \\
\text { mahasiswa memakai } \\
\text { toga dan hotline } \\
\text { Perguruan Tinggi } \\
\text { Raharja. }\end{array}$ \\
\hline
\end{tabular}

\section{Storyboard}

Storyboard berisikan rangkaian jalannya cerita yang berupa sketsa gambar dan dilengkapi dengan petunjuk pengambilan gambar. Yang nantinya akan digunakan selama proses sebelum melakukan shooting. Sehingga kita mempunyai acuan atau gambaran selama proses produksi.

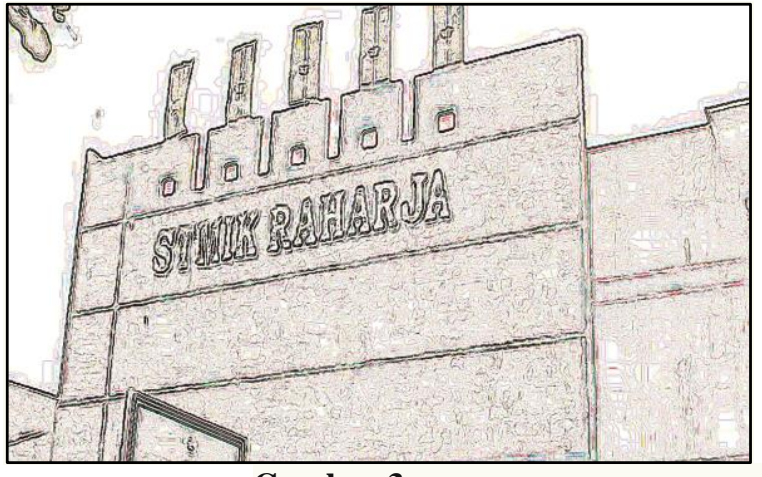

Gambar 3.

Bumper Opening menampilkan gedung depan STMIK Raharja.

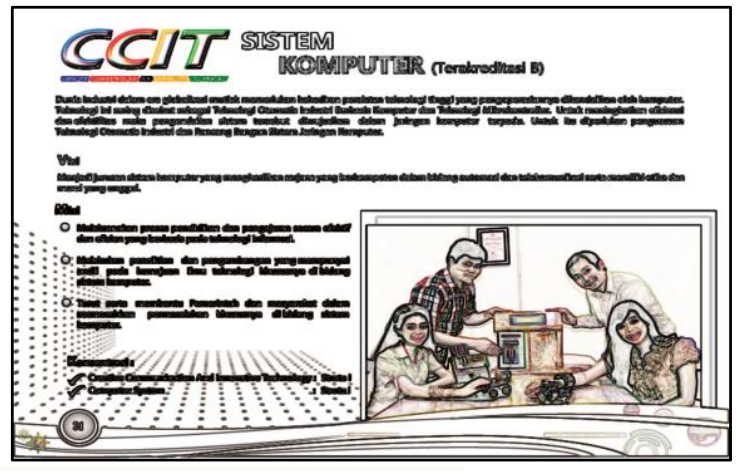

Gambar 4.

Menampilkan Visi dan Misi Jurusan Sistem Komputer STMIK Raharja. 


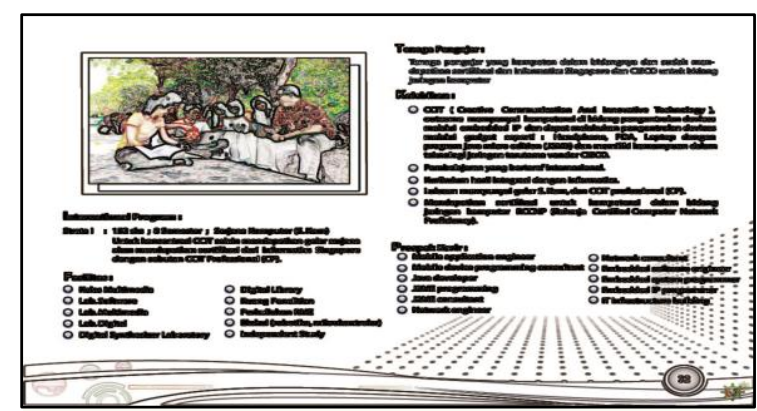

Gambar 5.

Menampilkan Kualifikasi Tenaga Pengajar Jurusan SK,Kelebihan, Fasilitas, Prospek Karir.

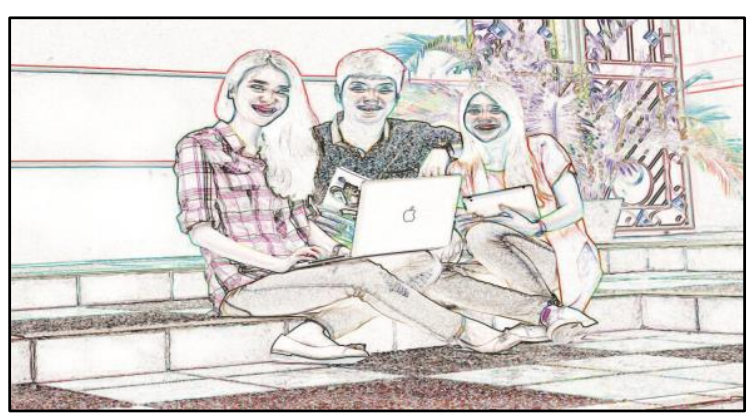

Gambar 8.

Menampilkan Mahasiswa SK

Sedang belajar menggunakan metode iLearning.

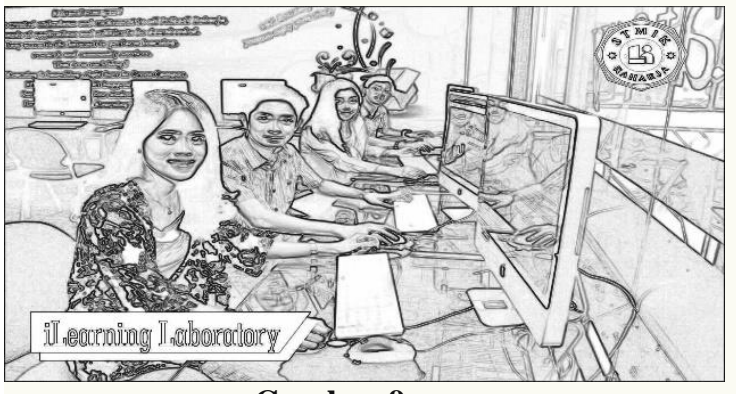

Gambar 9.

Menampilkan mahasiswa di Lab iLearning.

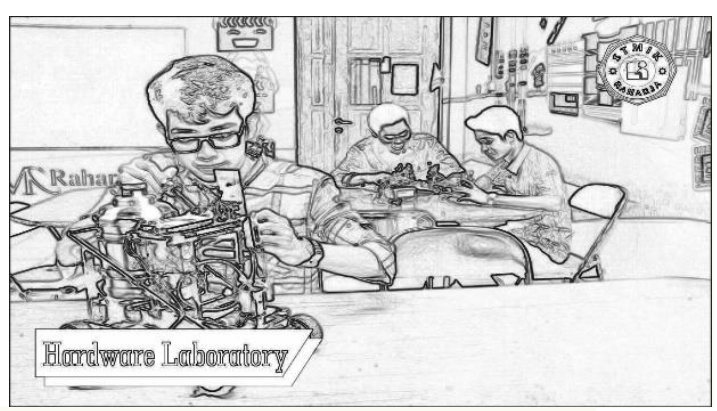

Gambar 6.

Menampilkan Mahasiswa SK sedang Merakit robot.

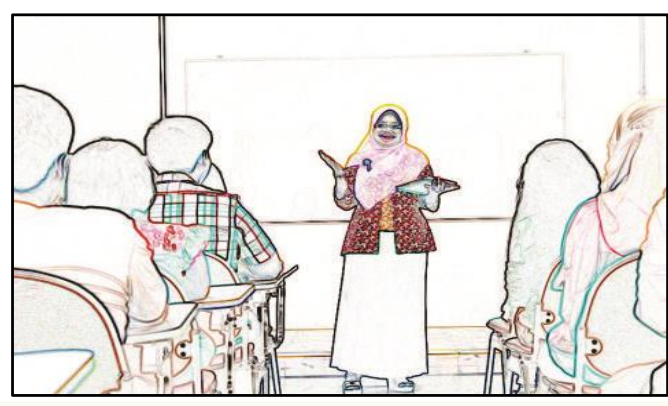

Gambar 7.

Menampilkan Dosen sedang mengajar dikelas.

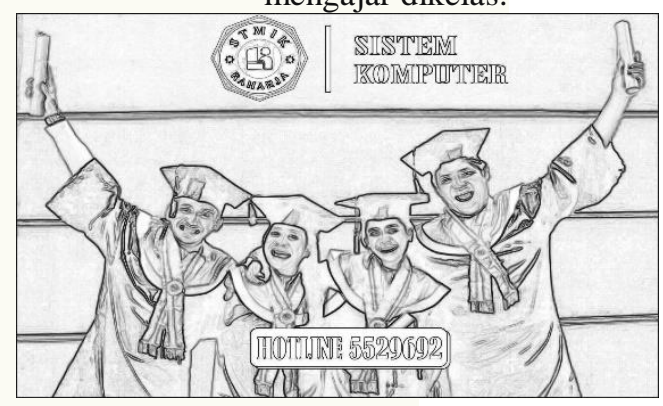

Gambar 10.

Menampilkan mahasiswa

Memakai toga dan hotline Perguruan Tinggi Raharja

\section{Produksi Crew \& Talent}

Di dalam perancangan video profile Sistem Komputer STMIK Raharja Crew \& Talent sangat di butuhkan sutradara, asisten sutradara, script writting, cameraman, editor, dubber, dan pemeran dari video profile Sistem Komputer ini adalah Mahasiswa/i STMIK Raharja, serta Dosen.

\section{Setting Alat}

Dalam perancangan video profil jurusan Sistem Komputer menggunakan peralatan seperti kamera, tripod, dan slider. Untuk kamera yang digunakan adalah Canon 600D. Pembuatan video promosi ini juga menggunakan lokasi indoor dan outdoor. Dubbing meggunakan perangkat ipad dengan aplikasi microphone recording pro. 


\section{Production}

Tabel 3. Time Schedule

\begin{tabular}{|c|c|c|c|c|c|c|c|c|c|c|c|c|c|c|c|c|c|}
\hline \multirow{2}{*}{ Tahapan } & & \multicolumn{4}{|c|}{$\operatorname{Des}(2017)$} & \multicolumn{4}{|c|}{$\operatorname{Jan}(2018)$} & \multicolumn{4}{|c|}{ Feb(2018) } & \multicolumn{4}{|c|}{$\operatorname{Mar}(2018)$} \\
\hline & & 1 & 2 & 3 & 4 & 1 & 2 & 3 & 4 & 1 & 2 & 3 & 4 & 1 & 2 & 3 & 4 \\
\hline \multirow{7}{*}{ 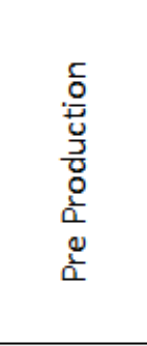 } & Ide & & & & & & & & & & & & & & & & \\
\hline & Time Schedule & & & & & & & & & & & & & & & & \\
\hline & Sinopsis & & & & & & & & & & & & & & & & \\
\hline & Script Writing & & & & & & & & & & & & & & & & \\
\hline & Storyboard & & & & & & & & & & & & & & & & \\
\hline & Pemilihan Talent and Crew & & & & & & & & & & & & & & & & \\
\hline & Setting Alat & & & & & & & & & & & & & & & & \\
\hline \multirow{4}{*}{ 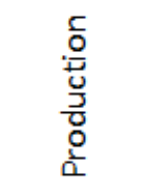 } & Perancangan Multimedia & & & & & & & & & & & & & & & & \\
\hline & Perancangan Audio & & & & & & & & & & & & & & & & \\
\hline & Perancangan Visual & & & & & & & & & & & & & & & & \\
\hline & Perancangan Broadcasting & & & & & & & & & & & & & & & & \\
\hline \multirow{5}{*}{ 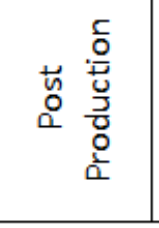 } & & & & & & & & & & & & & & & & & \\
\hline & Capturing, Editing, Mixing, & & & & & & & & & & & & & & & & \\
\hline & dan Finishing & & & & & & & & & & & & & & & & \\
\hline & & & & & & & & & & & & & & & & & \\
\hline & & & & & & & & & & & & & & & & & \\
\hline
\end{tabular}

Tahapan Production adalah proses yang sudah memasuki tahap penyusunan dan pengeditan yang menghasilkan sebuah project video. Dimana kerjasama antara talent dan crew sangat diperlukan agar proses produksi berjalan lancar. Production memiliki empat langkah berupa perencanaan, multimedia, audio visual dan perencanaan broadcasting yang berhungan dengan pengimplementasian video profile ini. Peran sutradara sangat penting dalam tahapan ini untuk mengatur maupun mengarahkan para talent yang ikut terlibat dan alur cerita agar sesuai dengan tahapan yang sudah dibuat sebelumnya.

\section{Post Production}

Post Production merupakan langkah terakhir diantara tahapan tahapan yang dibuat sebelumnya yaitu preproduction, production, dan post production. langkah post production bisa disebut juga sebagai tahap finishing sebuah hasil project sampai menjadi karya yang utuh. Dan mampu menyampaikan pesan terhadap audience. Pada tahapan ini dilakukan proses editing yang meliputi suara, gambar, dan alur cerita sesuai sinopsis video profile yang dibuat pada saat proses produksi.

\section{Tampilan Isi}

Tampilan isi ini mengambil dari jalan cerita yang telah telah dirancang pada saat pembuatan sinopsis. Dan juga meliputi aktifitas mahasiswa CCIT dan COS pada saat perkuliahan. Tabel berikut menjelaskan tentang tampilan isi video yang telah dibuat pada saat proses perancangan KPM.

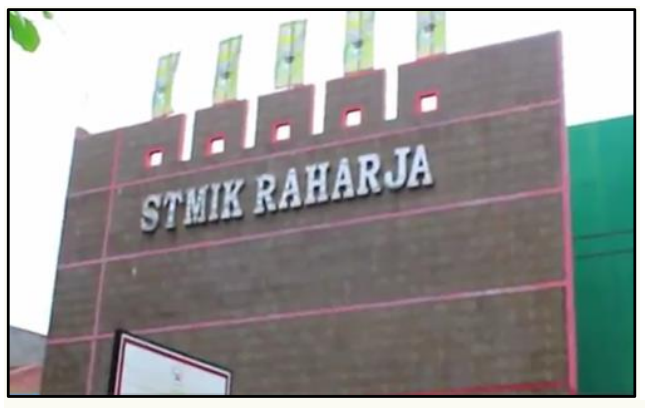

Gambar 11

Bumper Opening menampilkan

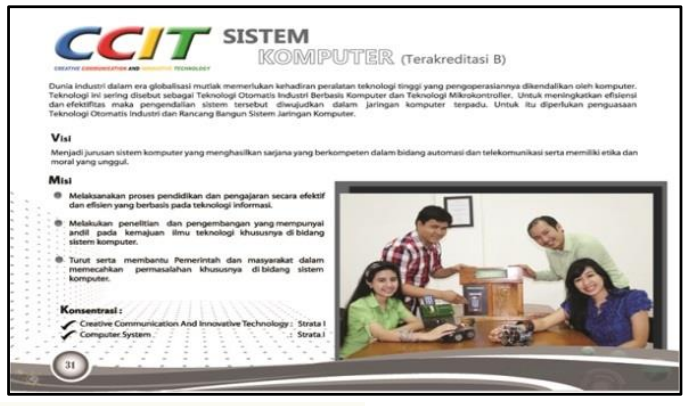

Gambar 12.

Menampilkan Visi dan Misi Jurusan 


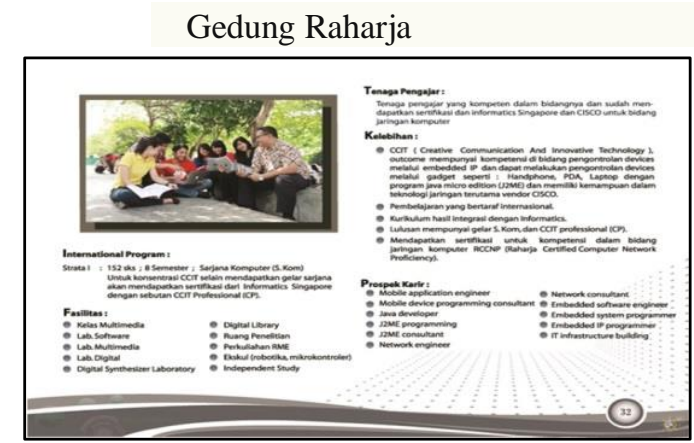

Gambar 14.

Menampilkan Kualifikasi Tenaga Pengajar Jurusan SK, Kelebihan, Fasilitas, Prospek Karir

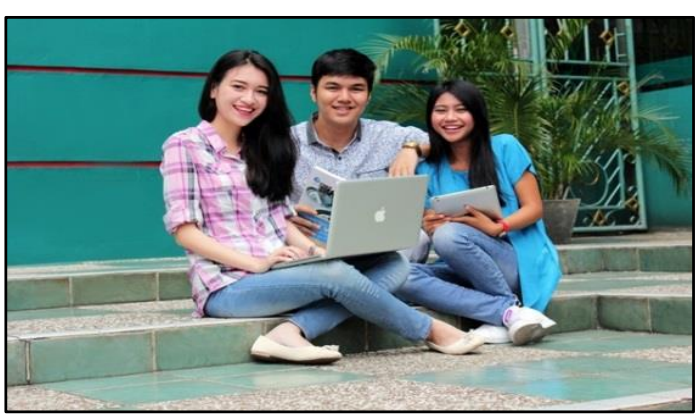

Gambar 15.

Menampilkan mahasiwa SK sedang. Belajar menggunakan metode iLearning.

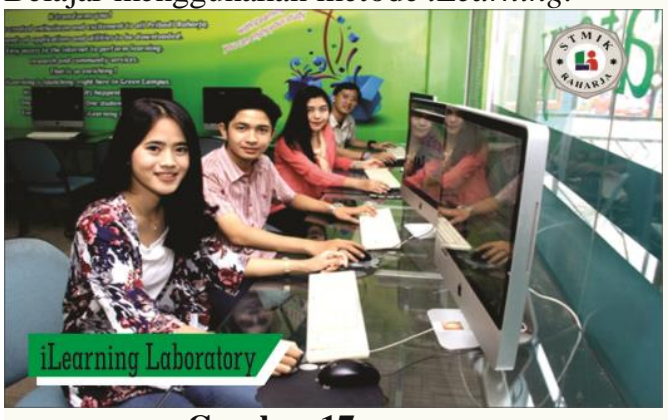

Gambar 17.

Menampilkan mahasiswa di Lab iLearning.
Sistem Komputer STMIK Raharja.

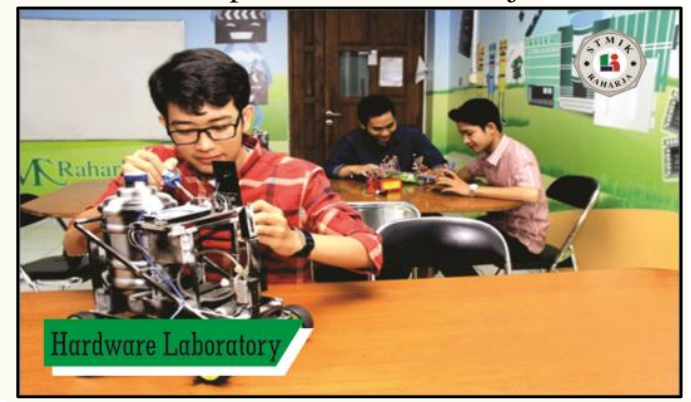

Gambar

13.

Menampilkan mahasiswa SK sedang Merakit Robot.

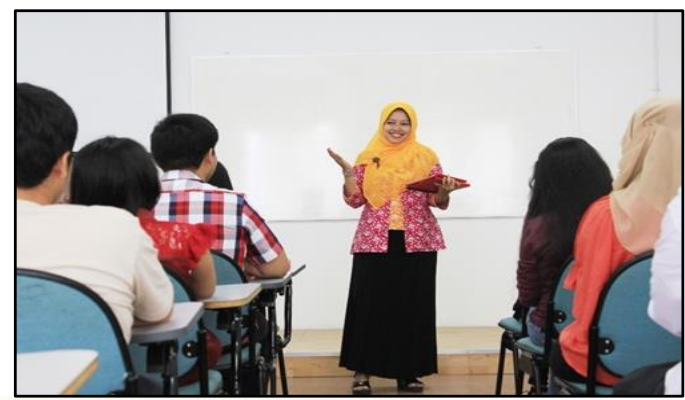

Gambar 16.

Menampilkan dosen sedang Mengajar dikelas.

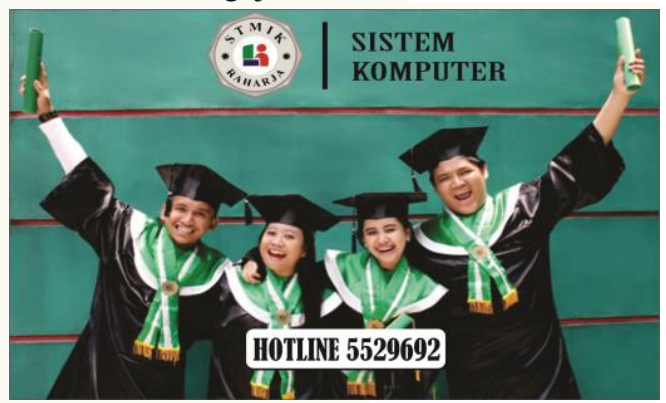

Gambar 18.

Menampilkan mahasiswa

memakai toga \& Hotline Perguruan Tinggi Raharja.

\section{KESIMPULAN}

Media informasi dan promosi yang dibutuhkan pada jurusan Sistem Komputer STMIK Raharja adalah video profile yang menggunakan alur cerita yang menarik yang tentunya dipadukan dengan unsur gerak, gambar, music, dan effect yang cinematic, yang menjelaskan tentang Profil Jurusan Sistem Komputer, Visi, Misi, dan Konsentrasi Jurusan SK, kualifikasi tenaga pengajar di Jurusan SK, Kelebihan, Fasilitas dan Prospek Karir lulusan Jurusan SK, Proses pembelajaran Jurusan SK pada Lab. Digital, Lab. iLearning, dan Ruang Kelas, Keunggulan Jurusan SK yaitu metode pembelajaran iLearning dengan menggunakan fasilitas $i \mathrm{Pad}$.

Pada video ini juga dilakukan pendekatan kepada penonton dengan memberikan sequence drama untuk membuat ketertarikan minat calon mahasiswa untuk bergabung pada Jurusan Sistem Komputer STMIK Raharja sekaligus menjadi identitas jurusan SK agar dikenal masyarakat luas. Strategi pemasaran pada video ini adalah akan ditayangkan pada social media berupa youtube, facebook, dan berbagai event di Perguruan Tinggi Raharja. Melalui perancangan video profile jurusan Sistem 
Komputer Jenjang Strata Satu STMIK Raharja ini, diharapkan akan meningkatkan angka pendaftaran setiap tahunnya khususnya pada jurusan Sistem Komputer STMIK Raharja.

\section{SARAN}

Dengan adanya Video Profile jurusan Sistem Komputer STMIK Raharja diharapkan dipergunakan dengan baik dan diperbarui agar visi dan misi jurusan SK STMIK Raharja Tangerang bisa tercapai.

Disarankan kepada jurusan Sistem Komputer STMIK Raharja untuk terus melakukan promosi dengan konsep video profile yang menarik karena masyarakat pada umumnya mudah bosan untuk menyimak sebuah informasi yang kurang menarik dan tentunya disesuaikan dengan informasi terupdate profil Jurusan SK STMIK Raharja, yang bertujuan untuk memberi pengetahuan pada calon mahasiswa/i baru yang ingin memilih jurusan Sistem Komputer STMIK Raharja. agar memperluas pangsa pasar sehingga meningkatkan minat pendaftar pada jurusan Sistem Komputer STMIK Raharja. 


\section{DAFTAR PUSTAKA}

[1] Dewi, Surya dan A, Khumaidi, 2017, Pengenalan Perangkat Teknologi Informasi dan Komunikasi Bagi Anak Usia Dini pada Taman Kanak-Kanak (TK) Harapan Kita Kec. Pugung Menggunakan Aplikasi Multimedia Macromedia Flash. Prosiding KMSI. ISSN: 2337:3032. Vol.5 No. 1 : 563 Lampung : STMIK Pringsewu Lampung.

[2] Sunarya, Lusyani, Della Nurasiah dan Firmansyah Agustian, 2017, Video Profile Sebagai Sarana Informasi dan Promosi Studio Satu PT. Media Televisi Indonesia (Metro TV), Journal Cerita Vol.3 No.1, Tangerang, Perguruan Tinggi Raharja.

[3] Sunarya, Lusyani, Putri Aprylia, Siti Isnaini, 2016, Design Video Profile Based Multimedia Audio Visual and Broadcasting as A Media Promotion, CCIT Journal Vol.9 No.3, Tangerang, Perguruan Tinggi Raharja.

[4] Dhadang, Dheasey Amboningtyas dan Djamaluddin Malik, 2017, The Influence of Location, Price, and Promotion to Customer Loyalty. Journal of Management. ISSN: 2502-7689. Vol.3 No.3 : 3. Semarang : Universitas Pandanaran Semarang.

[5] Santoso, Budhi, 2014, Pembuatan Video Profil Smart Preschool Kepunton Solo, Vol.3 No.1, Indonesian Journal on Networking and Security.

[6] Mahmudi, Muh Ali, 2015, Pembuatan Video Profile Sekolah Dasar Negeri Tlogo CV Bootsector, Journal Speed Vol.7 No.3, Sentra Penelitian Engineering dan Edukasi.

[7] Zevri, Krisnawan, , 2014, Perancangan Media Promosi Jurusan Multimedia SMK Saraswati Salatiga Untuk Meningkatkan Jumlah Siswa Pendaftar, Universitas Dian Nuswantoro

[8] Sunarya, Lusyani, Rindang Kusumaninggar dan Adrian Syahputra, 2017, Perancangan Media Promosi Video Profile Pada SMA Negeri 15 Kota Tangerang, Eksplora Informatika Vol.6 No.2, Bali, STIKOM Bali.

[9] Haryanto, Tri dan Sarwo Nugroho , 2015, Perancangan Video Company Profile Sebagai Media Promosi Perusahaan Pada Pt. Propan Raya Icc Semarang, Pixel Vol.8 No.1, Semarang, Sekolah Tinggi Ilmu Elektronika dan Komputer Semarang 